\title{
WHAT PROFESSIONAL QUALITIES SHOULD A TEACHER HAVE IN THE CONDITIONS OF INCLUSIVE EDUCATION?
}

\author{
Nadezhda V. Shuvalova ${ }^{1 *}$, Svetlana V. Lezhenina ${ }^{2}$, Galina F. Gubanova ${ }^{3}$, Elena A. \\ Denisova $^{4}$, Alexander V. Moskovsky ${ }^{5}$, Olesia I. Moskovskaya ${ }^{6}$ \\ ${ }^{1}$ Prof, Chuvash State Pedagogical University, RUSSIA, naukacgu@gmail.com \\ ${ }^{2}$ Assoc. Prof., Chuvash State University, RUSSIA, svl-8@bk.ru \\ ${ }^{3}$ Assoc. Prof., Chuvash State University, RUSSIA, tanya-772@bk.ru \\ ${ }^{4}$ Assoc. Prof., Chuvash State University, RUSSIA, svl-8888@bk.ru \\ ${ }^{5}$ Prof, Chuvash State University, RUSSIA, priem kuez@mail.ru \\ ${ }^{6}$ Assoc. Prof., Chuvash State University, RUSSIA, alissmoskovskaya@yandex.ru \\ ${ }^{*}$ Corresponding Author
}

\begin{abstract}
The article considers the most significant professional qualities of teachers in the context of inclusive education. The legislation of the Russian Federation in the field of education in accordance with international standards provides for the possibility of any child with developmental disabilities receiving an inclusive education, by which, in accordance with Article 24 of the UN Convention on the Rights of Persons with Disabilities (hereinafter referred to as the Convention), ratified by the Russian Federation on September 24, 2008 (Federal Law of the Russian Federation of 03.05.2012 No. 46-FL "On Ratification of the Convention on the Rights of Persons with Disabilities"), we understand the organization of the learning process for all children, regardless of their physical, mental, intellectual, cultural, ethnic, linguistic and other characteristics, in the general education system at the place of residence together with their peers without disabilities in the same comprehensive schools, in such schools that take into account their special educational needs and provide their students with the necessary special support.

The aim of the research is to study what professional qualities a teacher should have in an inclusive education. Materials and methods of research: 57 teachers of special (correctional) general education schools (second level of education), working in the city of Cheboksary, the Chuvash Republic, the Russian Federation took part in the research. Period of the interview-questionnaire was 2018-2019. The study showed that almost half of teachers considered emotional stability as the most significant professional qualities in inclusive education, and a third of teachers noted psychological stability. Almost all teachers would like to develop these professional qualities. $72 \%$ of teachers answered that they experienced and are experiencing fear when working with children with disabilities, $15 \%$ - did not feel fear, $13 \%$ of the respondents found it difficult to answer. Perhaps this fear is associated with the low emotional stability of teachers. Thus, it is necessary to develop special programs aimed at reducing anxiety, stabilizing the emotional background. In addition, teachers need to attend various trainings, engage in auto-training, to develop special professional qualities. Only an integrated approach to this problem will make it possible to solve it optimally. Perhaps this will help reduce the fear level among teachers working with children with disabilities and increase the teachers' motivation to work in an inclusive education.
\end{abstract}

Keywords: Teacher, inclusive education, psychological stability, emotional stability, intellectual flexibility. 


\section{INTRODUCTION}

The legislation of the Russian Federation in the field of education in accordance with international standards provides for the possibility of any child with developmental disabilities receiving an inclusive education, by which, in accordance with Article 24 of the UN Convention on the Rights of Persons with Disabilities (hereinafter referred to as the Convention), ratified by the Russian Federation on September 24, 2008 (Federal Law of the Russian Federation of 03.05.2012 No. 46-FL "On Ratification of the Convention on the Rights of Persons with Disabilities"), we understand the organization of the learning process for all children, regardless of their physical, mental, intellectual, cultural, ethnic, linguistic and other characteristics, in the general education system at the place of residence together with their peers without disabilities in the same comprehensive schools, in such schools that take into account their special educational needs and provide their students with the necessary special support (Aisina, Nesterova, Suslova and Khitryuk, 2019, pp. 189210; Demyanchuk, 2020, 358 p.). However, the questions concerning the professional teachers' qualities in the changed working conditions remain insufficiently worked out (Alekhina, Semago and Fadina, 2010, 272 p.).

The aim of the research is to study what professional qualities a teacher should have in an inclusive education.

\section{MATERIALS AND RESEARCH METHODS}

The study involved 57 teachers of special (correctional) secondary schools (second level of education) working in the city of Cheboksary, the Chuvash Republic, the Russian Federation. Period of the interview questionnaire was 2018-2019. The age of the subjects ranged from 26 to 65 years (average age - $47.5+/-$ 7.5 years). An interview-questionnaire was created by the authors of the article. The subjects were asked the following questions:

1. What are the most significant professional qualities a teacher should have in an inclusive education?

2. Are these qualities fully developed in you?

3. Do you want to develop these qualities in yourself?

4. Do you experience fear when working with children with disabilities?

The results evaluation was carried out for each item of the questionnaire separately, as well as by calculating the arithmetic mean.

\section{RESULTS AND DISCUSSION}

In psychological and pedagogical research, a certain structure and approximate content of professionally important qualities that are significant for the diagnosis of personality and the effectiveness of the teacher's professional activity have been developed. In this structure, V.P. Simonov includes professional and personal qualities:

1) Psychological traits of personality as an individual;

2) A teacher in the structure of interpersonal relations;

3) Professional personality traits of the teacher;

4) Effectiveness of professional activity (Mitina, 2014, 376 p.).

R.I. Khmelyuk, Z.N. Kurlyand and N.A. Shevchenko use the term "psychological stability", which denotes a synthesis of properties and qualities of a person, which makes it possible to carry out their professional activities confidently and independently in various emotional conditions. To have psychological stability in pedagogical professional activity means to be able to navigate quickly in the changed conditions of school life, to find optimal solutions in complex non-standard psychological and pedagogical situations and at the same time maintain self-control and self-control.

Emotional stability is the ability to dose and maintain mental stress at a level that will provide each individual with optimal performance; on the nature of the activity and the success of its implementation; from the ability to correctly assess their strengths and find the optimal training load that ensures the success of educational activities.

Emotional stability (life satisfaction, lack of inclination to experience fear; lack of inclination to experience anger; partial emotional stability), positive emotional expressiveness (inclination to experience joy, self- 
sensitivity, spontaneity of manifestation of their states). The psychological condition for the development of emotional stability is, in our opinion, the teacher's awareness of the role and importance of the affective sphere of the personality in the optimization of activities, communication, mental and physical health of both teachers and students. Its dynamics is determined by the harmonization and complication of the teacher's affective manifestations: the ability to "revive" genuine emotions in a repetitive educational process, to evoke positive emotions (Pecherkina, 2011, 233 p.).

Intellectual flexibility is an increase in the level of the teacher's self-awareness, mainly of his cognitive component - self-knowledge.

In the study of L.V. Shargorodskaya it is showed that intellectual flexibility is a characteristic of a teacher's personality, which is a combination of individual behavior patterns and variable ways of role interaction. The psychological condition for the teacher's intellectual flexibility development is an increase in the level of the behavioral component of self-awareness - the possibilities of self-regulation, and the organizational and pedagogical condition - a specially designed psychological training (Mitina, 2015, 416 p.; Shargorodskaya, 2017, 229 p.).

The study showed that the most significant professional qualities in the conditions of inclusive education, teachers considered emotional stability, its importance was noted by 22 teachers (42.3\%), psychological stability was identified by 18 teachers (34.6\%), intellectual flexibility was indicated by 8 teachers (15, 4\%), other qualities -4 teachers $(7.7 \%)$.

When analyzing the interview-questionnaire to the second question: "Are these qualities fully developed in you?" the following results were obtained: $43(82.7 \%)$ teachers believed that they did not fully possess these qualities, 6 (11.5\%) respondents believed that they fully possessed these qualities; 3 (5.8\%) found it difficult to answer.

When analyzing the interview-questionnaire for the third question: "Do you want to develop these qualities in yourself?" 50 respondents $(96.2 \%)$ would like to develop such professional qualities as emotional stability, psychological stability and intellectual flexibility, 2 teachers $(3.8 \%)$ found it difficult to answer. The authors of the article consider this result important, since it indicates the teachers' readiness to acquire knowledge and develop in this direction.

When processing the data to the fourth question: "Do you experience fear when working with children with disabilities?" $37(71.1 \%)$ teachers answered that they felt and were afraid when working with children with deviations in health, 7 (13.5\%) - did not feel fear, 8 (15.4\%) of the respondents found it difficult to answer.

\section{CONCLUSION}

The study shows that almost half of teachers consider emotional stability as the most significant professional qualities in inclusive education, and a third of teachers noted psychological stability. Almost all teachers would like to develop these professional qualities. This conclusion is extremely important for understanding the essence of the problem. It is necessary to create special conditions for the teachers' professional qualities development in an inclusive education. It is necessary to develop special programs aimed at reducing anxiety, stabilizing the emotional background. Teachers need to attend various trainings, engage in auto-training, and provide them with various psychological support. Only an integrated approach to this problem will make it possible to solve it optimally. Perhaps this will help reduce the level of fear among teachers working with children with disabilities and increase the motivation of teachers to work in an inclusive education.

\section{REFERENCE LIST}

Aisina R. M., Nesterova A. A., Suslova T. F. and Khitryuk V. V. (2019). Attitudes of teachers in relation to inclusive education of children with races: a review of domestic and foreign studies. Education and Science, 21 (10).

Alekhina, S.V., Semago, N. Ya. and Fadina A.K. (2010). Inclusive education, Issue 1.

Demyanchuk, R. V. (2020). Personal and professional development of teachers and its psychological support.

Mitina, L.M. (2014). Psychology of personal and professional development of subjects of education. 
Proceedings of INTCESS 2022-9th International Conference on Education \& Education of Social Sciences 17-18 January 2022- Online Conference

Mitina, L.M. (2015). Psychological means of overcoming the difficulties of personal and professional development and preserving the health of subjects of education.

Pecherkina, A. A. (2011). Development of the teacher's professional competence: theory and practice: monograph.

Professional standard "Teacher (pedagogical activity in the field of preschool, primary general, basic general, secondary general education) (educator, teacher)" (as amended by the Order of the Ministry of Labor of Russia dated 05.08.2016 No. 422n).

Shargorodskaya, L.V. (2017). Organizational and pedagogical conditions for inclusive education of primary schoolchildren with autism spectrum disorders. 